\title{
Effects of Dichloroacetate on Pyruvate Metabolism in Rat Brain in Vivo
}

\author{
YASUHIRO KURODA, KENJI TOSHIMA, TOSHIYUKI WATANABE, HIDEAKI KOBASHI, \\ MICHINORI ITO, EIJI TAKEDA, AND MASUHIDE MIYAO
}

Department of Pediatrics, School of Medicine, University of Tokushima, Tokushima, Japan

\section{Summary}

The effects of dichloroacetate (DCA) on the activity of the pyruvate dehydrogenase (PDH) complex and associated changes in the lactate and glucose levels in rat brain were investigated in vivo. The average activities of the active form of the PDH complex in the brain, liver and muscle of starved rats were respectively $0.40 \pm 0.04,0.07 \pm 0.04$, and $0.17 \pm 0.11 \mu \mathrm{mol} /$ $\mathrm{min} / \mathrm{g}$ tissue, and amounted to 21,11 , and $16 \%$ of the total activity of the complex. Intraperitoneal injection of DCA (125 $\mathrm{mg} / \mathrm{kg}$ ) increased the percentage of the active form of the PDH complex in the brain, liver, and muscle to 107,40 , and $84 \%$, respectively. DCA significantly lowered the lactate and glucose concentrations of the brain and blood. A lower dose of DCA (12.5 $\mathrm{mg} / \mathrm{kg}$ ) also caused significant increase in activity of the PDH complex in the brain, but did not significantly change the lactate or glucose concentration of the brain. These results suggest that DCA crosses the blood-brain barrier reasonably well.

\section{Abbreviations}

PDH, pyruvate dehydrogenase

DCA, dichloroacetate

Chronic congenital lactic acidosis of childhood is characterized by persistently high levels of blood pyruvate and lactate. Dietary control and other rational biochemical manipulations have been tried in attempts to lower the blood lactate level in patients with this disease, but with only limited success (2). In two patients with chronic lactic acidosis due to defects of pyruvate carboxylase (EC 6.4.1.1) and PDH (EC 1.2.4.1), the blood lactate and pyruvate were reduced to nearly normal levels by lipoic acid and dietary therapy, but despite this therapy the levels of lactate and pyruvate in the cerebrospinal fluid remained high, and neurologic deterioration continued $(11,16)$. Usually, the lactate and pyruvate levels in the cerebrospinal fluid are also elevated in patients with chronic congenital lactic acidosis. Therefore, it may be important to maintain the lactate level within a normal range not only in the blood but also in the cerebrospinal fluid in therapy of chronic congenital lactic acidosis.

DCA is known to activate the PDH complex in various tissues in vitro by inhibiting PDH kinase (EC 2.7.1.99) (1, 5, 13). Moreover, administration of DCA to man and animals reduces the blood levels of lactate, pyruvate, and alanine by its action on PDH $(6,15,17)$. Therefore, this drug has been used in attempts to treat chronic congenital lactic acidosis in humans $(4,12,14)$. At the doses of DCA used, no neurologic improvement was observed during DCA therapy, although the blood lactate level

Received March 16, 1984

Requests for reprints should be addressed to Dr. Y. Kuroda, Department of Pediatrics, School of Medicine, University of Tokushima, 2-Kuramoto-cho, Tokushima 770, Japan.

This study was supported by Grant $82-08$ from the National Center for Nervous, Mental, and Muscular Disorders of the Ministry of Health and Welfare of Japan. was lowered. However, the effect of DCA on the lactate level in the cerebrospinal fluid in the patients has not been reported.

Therefore, we investigated the in vivo effects of small and large doses of DCA on the activity of the PDH complex in the brain and consequent changes in the lactate and glucose levels in rats.

\section{MATERIALS AND METHODS}

Animals. Male Wistar rats weighing 170-195 g were given free access to water and laboratory chow.

Chemicals. Sodium DCA was obtained from Tokyo Kasei Kogyo Co., (Tokyo, Japan) and $\left[1-{ }^{14} \mathrm{C}\right]$ pyruvate was from New England Nuclear Corp. All other chemicals were from Sigma Chemical Co. and Boehringer-Mannheim, Yamanouchi K.K.

Animal experiments. The rats were deprived of food for $24 \mathrm{~h}$ and then anesthetized by intraperitoneal injection of Nembutal $(60 \mathrm{mg} / \mathrm{kg})$. They were then given $0.25 \mathrm{ml}$ of $0.9 \% \mathrm{NaCl}$ or 0.5 or $5 \%(\mathrm{w} / \mathrm{v})$ sodium DCA/100 $\mathrm{g}$ by intraperitoneal injection. This injection was repeated 30,90 , and 150 min later. A sample of $1 \mathrm{ml}$ of blood was taken from the abdominal aorta at 180 min. Then the rats were decapitated and samples of liver and psoas muscle were rapidly removed. The head and these tissues were immediately immersed in liquid nitrogen. A sample of brain was quickly removed from the frozen head in a cold room. These tissues were stored at $-70^{\circ} \mathrm{C}$ for analyses.

Assay of metabolites. Blood and tissue samples were deproteinized with 2 and 6 volumes of $4 \%(\mathrm{w} / \mathrm{v})$ perchloric acid, respectively, and the deproteinized supernatants were used for measurement of lactate. The supernatant was neutralized and perchlorate was precipitated with $2 \mathrm{~N} \mathrm{KOH}$ for measurement of glucose. Lactate and glucose concentrations were measured enzymatically $(7,10)$. Blood glucose was determined with an assay kit (Fujisawa, Japan).

Assay of PDH complex. PDH complex activity was determined by a modification of the technique of Leiter et al. (9) for rat liver mitochondria with assay mixture consisting of $30 \mathrm{mM}$ potassium phosphate, pH 7.5, 2 mM $\mathrm{MgCl}_{2}, 2.5 \mathrm{mM}$ NAD, $0.8 \mathrm{mM} \mathrm{Co}-$ ASH, $0.4 \mathrm{mM}$ thiamine pyrophosphate, $2 \mathrm{mM}$ dithiothreitol, $0.01 \%$ Triton $\mathrm{X}-100$, and $2 \mathrm{mM}\left[1-{ }^{14} \mathrm{C}\right]$ pyruvate $(0.1 \mathrm{mCi}$ ) $\mathrm{mmol})$. Tissues were homogenized with 50 volumes of the homogenizing buffer in a glass-Teflon homogenizer (3), and the activity of the PDH complex was then promptly assayed. Total PDH complex activity was assayed after in vitro activation of the complex with a broad specificity protein phosphatase, which was a partially purified preparation from rabbit liver (8). Activation was complete after preincubation for $10 \mathrm{~min}$ (data not shown).

\section{RESULTS}

Table 1 summarizes the effects of intraperitoneal administration of DCA on the activity of the PDH complex in various tissues of rats that had been starved overnight. The average activities of the brain, liver, and muscle of the control group were $0.40 \pm 0.04,0.07 \pm 0.04$, and $0.17 \pm 0.11 \mu \mathrm{mol} / \mathrm{min} / \mathrm{g}$ 
tissue, respectively, representing 21,11 , and $16 \%$ of the total activities in these tissues. A large dose of DCA $(125 \mathrm{mg} / \mathrm{kg}$ body weight) caused significant activation of the PDH complex in each of these tissues, the per cent activities in the brain, liver, and muscle increasing to 107,40 , and $84 \%$, respectively. A smaller dose DCA (12.5 mg/ $\mathrm{kg}$ body weight) also caused a significant increase in the activity in the brain, but not in the liver or muscle. Thus, the effect of DCA on the PDH complex activity was greatest in the brain. The total PDH complex activities in these tissues were not significantly changed by administration of a large dose of DCA.

Table 2 shows the effects of DCA on the lactate and glucose concentrations of the brain and blood of starved rats. Intraperitoneal injection of the larger dose of DCA lowered the lactate and glucose concentrations in the brain and blood, whereas injection of the smaller dose of DCA did not significantly change the brain lactate or glucose concentration or the blood lactate concentration, although it decreased the blood glucose concentration slightly.

\section{DISCUSSION}

Dichloroacetate is known to inhibit PDH kinase and consequently to increase the activity of PDH by decreasing its endogenous phosphorylation in the brain and other tissues in vitro ( 1 , $5,13)$. As shown in the present study, intraperitoneal administration of DCA $(125 \mathrm{mg} / \mathrm{kg}$ ) caused significant increase in PDH complex activity in the brain and other tissues and lowered the lactate levels in both the blood and brain in vivo. A lower dose of DCA $(12.5 \mathrm{mg} / \mathrm{kg})$ also caused significant increase in activity of the PDH complex in the brain. These results suggest that DCA crosses the blood-brain barrier reasonably well.

In the present study on normal rats after overnight starvation, intraperitoneal injection of DCA $(125 \mathrm{mg} / \mathrm{kg})$ lowered the glucose levels in the blood and brain. It has been suggested that DCA, by activating PDH and pyruvate oxidation, may interfere with the release of lactate and alanine from peripheral tissues and impair gluconeogenesis in the liver and kidney (17). Hypoglycemia could thus result from interruption of the Cori and alanine cycle. However, the decrease in the glucose level in the

Table 1. Effect of DCA administration on PDH complex activity in various tissues*

Pyruvate dehydrogenase complex

\begin{tabular}{cccc}
\multirow{2}{*}{$\begin{array}{c}\text { Tissue and } \\
\text { group }\end{array}$} & \multicolumn{2}{c}{$(\mu \mathrm{mol} / \mathrm{min} / \mathrm{g}$ tissue $)$} & $\begin{array}{c}\% \text { of } \\
\text { active form }\end{array}$ \\
\cline { 2 - 3 } & Active form & Total & \\
Brain & & & 21 \\
Control & $0.40 \pm 0.04$ & $1.88 \pm 0.25$ & 31 \\
DCA 1 & $0.64 \pm 0.12 \ddagger$ & $2.08 \pm 0.53$ & 107 \\
DCA 2 & $2.12 \pm 0.12 \S$ & $1.99 \pm 0.19$ & \\
Liver & & & \\
Control & $0.07 \pm 0.04$ & $0.66 \pm 0.19$ & 11 \\
DCA 1 & $0.06 \pm 0.02$ & $0.75 \pm 0.13$ & 8 \\
DCA 2 & $0.40 \pm 0.17 \dagger$ & $0.99 \pm 0.13$ & 40 \\
Muscle & & & \\
Control & $0.17 \pm 0.11$ & $1.05 \pm 0.07$ & 16 \\
DCA 1 & $0.22 \pm 0.11$ & $0.82 \pm 0.24$ & 27 \\
DCA 2 & $0.93 \pm 0.19 \S$ & $1.11 \pm 0.26$ & 84 \\
\hline
\end{tabular}

* Rats were starved overnight and anesthetized by intraperitoneal injection of Nembutal $(60 \mathrm{mg} / \mathrm{kg})$. Then $0.9 \% \mathrm{NaCl}$ (control), $0.5 \%$ sodium DCA (DCA 1), or 5\% sodium DCA (DCA 2) was injected intraperitoneally $(0.25 \mathrm{ml} / 100 \mathrm{~g}$ body weight $)$ at $0,30,90$, and $150 \mathrm{~min}$. The head, liver, and muscle were removed from the rats at $180 \mathrm{~min}$ and frozen in liquid nitrogen. PDH complex activity in these tissues was assayed as described in the text. Results are given as means \pm SD for groups of five rats. $\dagger, \ddagger$, and $\S$ : significantly different from the value for controls at $p<0.02,<0.01$, and $<0.001$, respectively.
Table 2. Effect of DCA administration on blood and brain concentrations of lactate and glucose*

\begin{tabular}{lccccc}
\hline & \multicolumn{2}{c}{ Lactate } & & \multicolumn{2}{c}{ Glucose } \\
\cline { 2 - 3 } \cline { 5 - 6 } Group & $\begin{array}{c}\text { Brain } \\
(\mathrm{mmol} / \mathrm{kg} \text { tissue })\end{array}$ & $\begin{array}{c}\text { Blood } \\
(\mathrm{mM})\end{array}$ & & $\begin{array}{c}\text { Brain } \\
(\mathrm{mmol} / \mathrm{kg} \text { tissue })\end{array}$ & $\begin{array}{c}\text { Blood } \\
(\mathrm{mM})\end{array}$ \\
\hline Control & $3.03 \pm 0.42$ & $0.87 \pm 0.16$ & & $1.71 \pm 0.18$ & $6.46 \pm 0.32$ \\
DCA 1 & $3.14 \pm 0.56$ & $0.78 \pm 0.11$ & & $1.44 \pm 0.31$ & $5.98 \pm 0.22 \dagger$ \\
DCA 2 & $2.23 \pm 0.50 \dagger$ & $0.49 \pm 0.10 \ddagger$ & $1.01 \pm 0.23 \S$ & $4.33 \pm 0.38 \S$ \\
\hline
\end{tabular}

* Conditions were as for Table 1. At $180 \mathrm{~min}$, blood samples were collected from the abdominal aorta and the head was removed and frozen in liquid nitrogen. Lactate and glucose were analyzed as described in the text. Results are given as means \pm SD for groups of five rats. $\dagger, \ddagger$, and $\S$, significantly different from the value for controls at $p<0.05,<$ 0.005 , and $<0.001$, respectively.

brain might have been due not only to reduction in the blood glucose level but also to increased oxidation of glucose in the brain resulting from activation of $\mathrm{PDH}$.

The pyruvate concentration in the blood and brain were not determined in this study because attention was directed to the therapy of lactic acidosis. Evans and Stacpoole (6) have investigated the effect of DCA $(100 \mathrm{mg} / \mathrm{kg})$, administered intragastrically once daily for 7 days to fed rats, on the blood levels of lactate and pyruvate. They found that the blood levels of lactate and pyruvate were reduced below the basal levels within $3 \mathrm{~h}$ after the last dose of DCA. The degree of decrease in the blood pyruvate level was similar to that in the blood lactate level at 3 $\mathrm{h}$ after the final dose, but the blood lactate level remained significantly below the basal level for $24 \mathrm{~h}$ after DCA administration, whereas the blood pyruvate level remained low for only $6 \mathrm{~h}$ and had returned to the basal level by $24 \mathrm{~h}$ after DCA administration. Thus, the effect of DCA on the blood lactate level persisted for longer than that on the blood pyruvate level.

In therapy for congenital lactic acidosis, it is important to reduce the lactate level to normal not only in the blood but also in the cerebrospinal fluid. Therefore, our results suggest that DCA could be used to treat all forms of chronic congenital lactic acidosis except lactic acidosis due to a complete deficiency of the PDH complex. DCA has been used in attempts to treat chronic congenital lactic acidosis in humans. Coude et al. (4) and McKhann et al. (12) administered DCA (150 mg/kg/day and 15 $\mathrm{mg} / \mathrm{kg}$ every $2 \mathrm{nd}$ day) to an 18 -month-old baby and 12 -year-old child, respectively, with chronic congenital lactic acidosis due to a defect of PDH and Krebs cycle dysfunction (BH Robinson, personal communication). More recently, Robinson et al. (14) used DCA (50 mg/kg three times per day) to treat congenital lactic acidosis due to a defect in the reoxidation of cytoplasmically generated NAD in a 2-month-old girl (14). In all these patients, DCA reduced the blood lactate level, while the blood glucose level was only slightly reduced in two patients $(4,12)$. The lactate levels in the cerebrospinal fluid of these patients were not reported, but from our results, it seems probable that they were also decreased. Although neurologic deterioration was not effected by DCA therapy in these patients, further studies on appropriate doses and routes of administration of DCA and times of initiation of DCA therapy in more patients with chronic congenital lactic acidosis seem worthwhile, because DCA lowers the lactate level in not only the blood but also the brain.

Acknowledgment. The authors wish to thank Dr. Robert A. Harris (Department of Biochemistry, School of Medicine, Indiana University) for a gift of broad specificity protein phosphatase purified from rabbit liver.

\section{REFERENCES}

1. Baudry M, Kessler M, Smith EK, Lynch G 1982 The regulation of pyruvate dehydrogenase activity in rat hippocampal slices: effect of dichloroacetate. 
Neurosci Lett 31:41

2. Blass JP 1983 Inborn errors of pyruvate metabolism. In: Stanbury JB, Wyngaarden JB, Fredrickson DS, Goldstein JL, Brown MS (eds) The Metabolic Basis of Inherited Disease. McGraw-Hill Book Company, New York, pp 193-203

3. Blass JP, Cederbaum SD, Kark RAP 1977 Rapid diagnosis of pyruvate and ketoglutarate dehydrogenase deficiencies in platelet-enriched preparations from blood. Clin Chim Acta 75:21

4. Coude FX, Saudubray JM, Demangre F, Marsac C, Leroux JP 1978 Dichloroacetate as treatment for congenital lactic acidosis. N Engl J Med 299:1365

5. Crabb DW, Yount EA, Harris RA 1981 The metabolic effects of dichloroacetate. Metabolism 30:1024

6. Evans OB, Stacpoole PW 1982 Prolonged hypolactemia and increased total pyruvate dehydrogenase activity by dichloroacetate. Biochem Pharmacol 31:1295

7. Gutman I, Wahlgeld AW 1974 L-(+)-Lactate: determination with lactate dehydrogenase and NAD. In: Bergmeyer HU (ed) Methods of Enzymatic Analysis. Academic Press, New York, pp 1464-1468

8. Harris RA, Paxton R, Parker RA 1982 Activation of the branched-chain $\alpha$ ketoacid dehydrogenase complex by a broad specificity protein phosphatase. Biochem Biophys Res Commun 107:1497

9. Leiter AB, Weinberg M, Isohashi F, Utter MF 1978 Relationship between phosphorylation and activity of pyruvate dehydrogenase in rat liver mitochondria and the absence of such a relationship for pyruvate carboxylase. $J$

\section{Biol Chem 253:2716}

10. Lowry OH, Passonneau JV, Hasselberger FX, Schulz DW 1964 Effect of ischemia on known substrates and cofactors of the glucolytic pathway in brain. J Biol Chem 239:18

11. Maesaka H, Komiya K, Misugi K, Tada K 1976 Hyperalaninemia, hyperpyruvicemia and lactic acidosis due to pyruvate carboxylase deficiency of the liver: treatment with thiamine and lipoic acid. Eur J Pediatr 122:159

12. McKhann G, Francois B, Evrard P 1980 Long term use of low doses of dichloroacetate in a child with congenital lactic acidosis. Pediatr Res 14:167

13. Morgan DG, Routtenberg A 1982 Brain pyruvate dehydrogenase activity: regulation by phosphorylation-dephosphorylation. Brain Res 251:391

14. Robinson BH, Tayler J, Francois B, Beaudet AL, Peterson DF 1983 Lactic acidosis, neurological deterioration and compromised cellular pyruvate oxidation due to a defect in the reoxidation of cytoplasmically generated NADH. Eur J Pediatr 140:98

15. Stacpoole PW, Moore GW, Kornhauser DM 1978 Metabolic effects of dichloroacetate in patients with diabetes mellitus and hyperlipoproteinemia. N Engl J Med 298:526

16. Toshima K, Kuroda Y, Hashimoto T, Ito M, Watanabe Y, Miyao M, Ii K 1982 Enzymologic studies and therapy of Leigh's disease associated with pyruvate decarboxylase deficiency. Pediatr Res 16:430

17. Whitehouse S, Cooper RH, Randle PJ 1974 Mechanism of activation of pyruvate dehydrogenase by dichloroacetate and other halogenated carboxylic acids. Biochem J 141:761

\title{
The Onset of Breathing at Birth Stimulates Pulmonary Vascular Prostacyclin Synthesis
}

\author{
CHARLES W. LEFFLER, JACK R. HESSLER, AND ROBERT S. GREEN \\ Departments of Physiology and Biophysics [C.W.L., J.R.H., R.S.G.] and Pediatrics-Newborn Center [R.S.G.], \\ University of Tennessee Center for the Health Sciences, Memphis, Tennessee 38163
}

\section{Summary}

The purpose of the present study was to determine if pulmonary prostacyclin synthesis was stimulated by spontaneous onset of breathing by unanesthetized fetuses at birth. Cannulae were implanted and flow cuffs placed in fetal lambs and goats $(0.93$ term). Fetuses were delivered by cesarean section at 0.95 term and began breathing spontaneously. Prostacyclin in blood was determined by radioimmunoassay of its hydrolysis product, 6ketoprostaglandin $F_{1 \alpha}$ using methods that produced the same values in duplicate samples as did gas chromatography with electron capture detection. Fetal pulmonary prostacyclin production (left lung) [(left pulmonary venous concentration - pulmonary arterial concentration) $\times$ left pulmonary blood flow] was undetectable $\left[-1.7 \pm 1.0(\mathrm{SEM}) \mathrm{ng} \mathrm{PGI}_{2} \cdot \mathrm{kg}^{-1} \cdot \mathrm{min}^{-1}\right]$ and fetal pulmonary vascular resistance (left lung) high $(5.1 \pm 0.9 \mathrm{~mm}$ $\left.\mathrm{Hg} \cdot \mathrm{kg} \cdot \mathrm{min} \cdot \mathrm{ml}^{-1}\right)$. Pulmonary prostacyclin production increased to $30.1 \pm 12.3 \mathrm{ngPGI} \cdot \mathrm{kg}^{-1} \cdot \mathrm{min}^{-1}$ and pulmonary vascular resistance declined to $0.5 \pm 0.1 \mathrm{~mm} \mathrm{Hg} \cdot \mathrm{kg} \cdot \mathrm{min} \cdot \mathrm{ml}^{-1} 15 \mathrm{~min}$ after

Received November 4, 1983; accepted March 13, 1984.

Correspondence may be addressed to Dr. Charles W. Leffler, University of Tennessee Center for the Health Sciences, Department of Physiology and Biophysics, 894 Union Avenue (426 NA), Memphis, TN 38163.

This work was done during the tenure of an Established Investigatorship from the American Heart Association (C. W. L.) and with funds contributed in part by the Tennessee Affiliate. The research was supported in part by National Institutes of Health Grant HL22639, a grant-in-aid from the American Heart Association with funds contributed in part by the Tennessee Affiliate, a grant-in-aid from the Tennessee Lung Association, and Biomedical Research Support Grant from the University of Tennessee College of Medicine. birth. Pulmonary vascular resistance remained low even though pulmonary prostacyclin production fell $2-5 \mathrm{~h}$ after birth. These results, coupled with earlier studies using indomethacin to inhibit prostaglandin synthesis, support the hypothesis that pulmonary prostacyclin synthesis participates in the decline of pulmonary vascular resistance that accompanies the onset of ventilation at birth, but may be less important in maintenance of low pulmonary vascular resistance once reduced pulmonary vascular tone has been established.

\section{Abbreviations}

PG, prostaglandin

TX, thromboxane

GC-ECD, gas chromatography-electron capture detection RIA, radioimmunoassay

Reduction of pulmonary vascular resistance with the onset of breathing at birth allows right ventricular blood to pass through the pulmonary circulation and, thus, pulmonary gas exchange to occur. In anesthetized, exteriorized, fetal lamb preparations, Cassin et al. (4) found that rhythmic ventilation with a gas, increasing $\mathrm{PO}_{2}$, and decreasing $\mathrm{PCO}_{2}$ (increasing $\mathrm{pH}$ ) all contribute to the pulmonary vasodilation. In a similar preparation, ventilation-induced pulmonary vasodilation at birth consisted of a rapid decline in the first $30 \mathrm{sec}$ followed by a slower, more prolonged vasodilation over the first $20 \mathrm{~min}$ or more (13). 